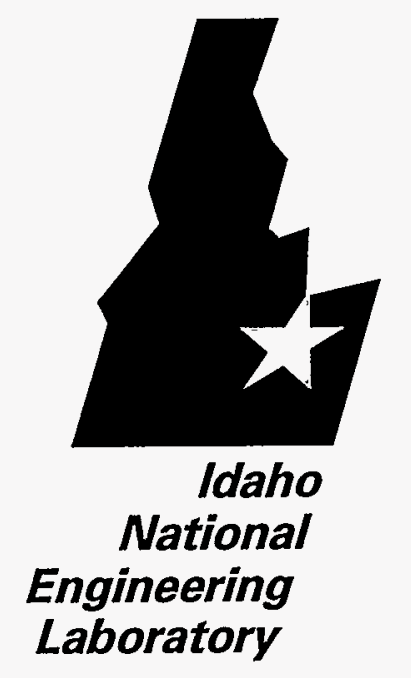

INEL-96/0161

May 1996

\title{
Time Card Entry System
}

\author{
necenta \\ Mบ 22 คิ⺈ \\ OSTI
}

B. S. Montierth 


$$
\text { INEL- } 96 / 0161
$$

INEL 96/0161

\section{Time Card Entry System}

B. S. Montierth

Published May 1996

\section{Idaho National Engineering Laboratory Programmatic Software Development Department Lockheed Martin Technologies Company Idaho Falls, Idaho 83415}




\begin{abstract}
The Time Card Entry System was developed to interface with the DOE Headquarters Electronic Time and Attendance (ETA) system. It features pop-up window pick lists for Work Breakdown Structure Numbers and Hour Codes and has extensive processing that ensures that time and attendance reported by the employee fulfills U.S. Government/OMB requirements before Timekeepers process the data at the end of the two week payroll cycle using ETA. Tours of Duty (e.g. ten hour day, four day week with Friday through Sunday off), established in the ETA system, are imported into the Time Card Entry System by the Timekeepers. An individual's Tour of Duty establishes the basis for validation of time of day and number of hours worked per day. At the end of the two week cycle, data is exported by the Timekeepers from the Time Card Entry System into ETA data files.
\end{abstract}

\title{
DISCLAIMER
}

This report was prepared as an account of work sponsored by an agency of the United States Government. Neither the United States Government nor any agency thereof, nor any of their employees, makes any warranty, express or implied, or assumes any legal liability or responsibility for the accuracy, completeness, or usefulness of any information, apparatus, product, or process disclosed, or represents that its use would not infringe privately owned rights. Reference herein to any specific commercial product, process, or service by trade name, trademark, manufacturer, or otherwise does not necessarily constitute or imply its endorsement, recommendation, or favoring by the United States Government or any agency thereof. The views and opinions of authors expressed herein do not necessarily state or reflect those of the United States Government or any agency thereof. 


\section{Table of Contents}

SYSTEM ACCESS

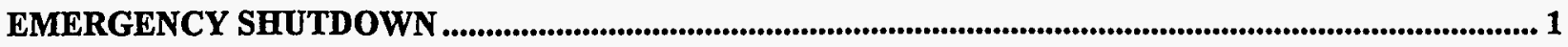

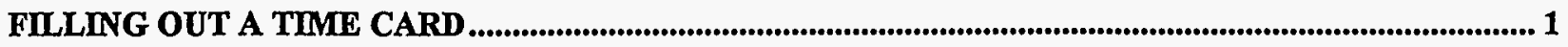

USING THE GRIDS WHEN FILLING OUT A TIMECARD..................................................................................... 1

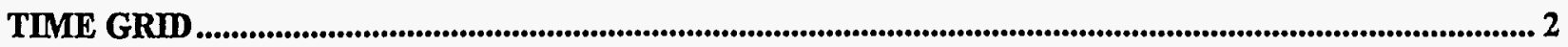

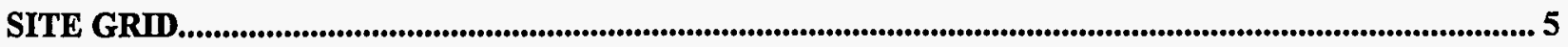

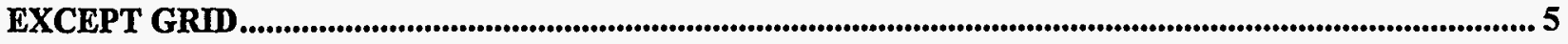

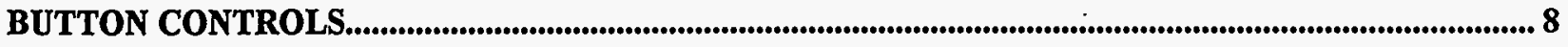

ADDING LINES

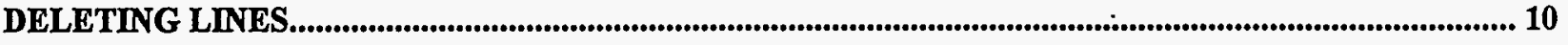

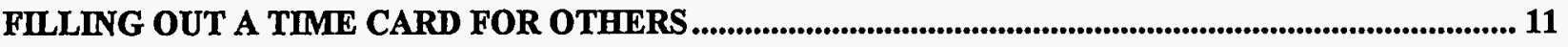

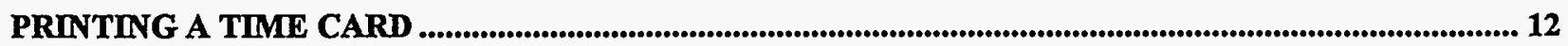

ASSIGNING EMPLOYEES TO TIMEKEEPERS

LOOKING UP AN EMPLOYEE-TIMEKEEPER ASSIGNMENT ............................................................................ 14

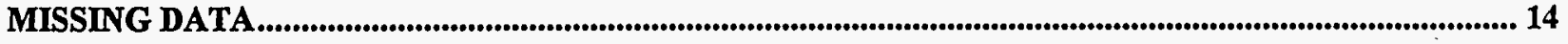

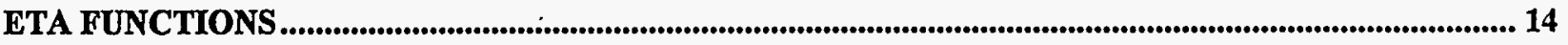

TABLE AND SYSTEM VARIABLES MAINTENANCE

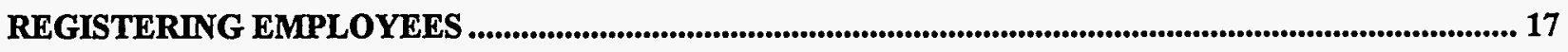

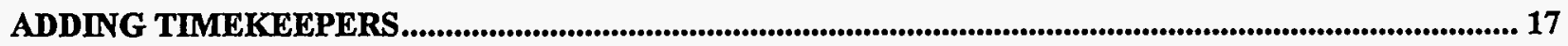

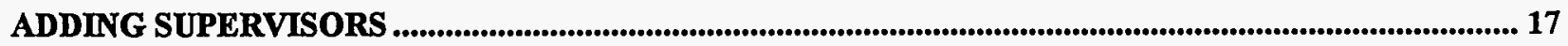

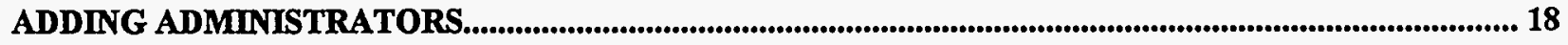

PERFORMANCE

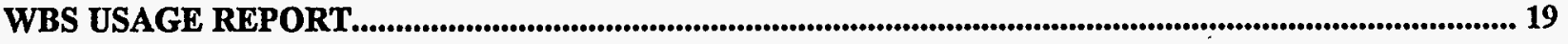




\section{System Access}

Access to the Timecard system first requires that the employee be logged on correctly to the network and that an employee be in the Employee file. All Employees may access the File menu. Access to other menus requires membership in one of the groups: Timekeeper, Supervisor or Administrator. Members of the Timekeeper group may access the File and Timekeeper menu. Members of the Supervisor group may access the File and Supervisor menu. Members of the Administrator group may access all menus. Timekeepers may add other Timekeepers, but only an Administrator can add Employees, Supervisors, or other Administrators.

\section{Emergency Shutdown}

Although the normal way to exit the system is through Exit from the File menu, Timecard can be terminated at any time, without loss of Timecard data, by pressing Ctrl-F4.

\section{Filling out a Time Card}

An Employee may work only on a timecard for the current week. To fill out the current week's timecard, an Employee selects Current Timecard from the File menu. If an Employee forgets to submit his timecard, his Timekeeper can submit past due Time Cards by using an option on the Timekeeper menu. If an Employee needs to change a Time Card which has already been submitted, he must contact the Timecard Administrator who can unsubmit a Time Card. This option must be used with care, however, since the Employee's Timekeeper may have already completed processing Time Cards, based on what was submitted.

Screen for Entering Time Card Data

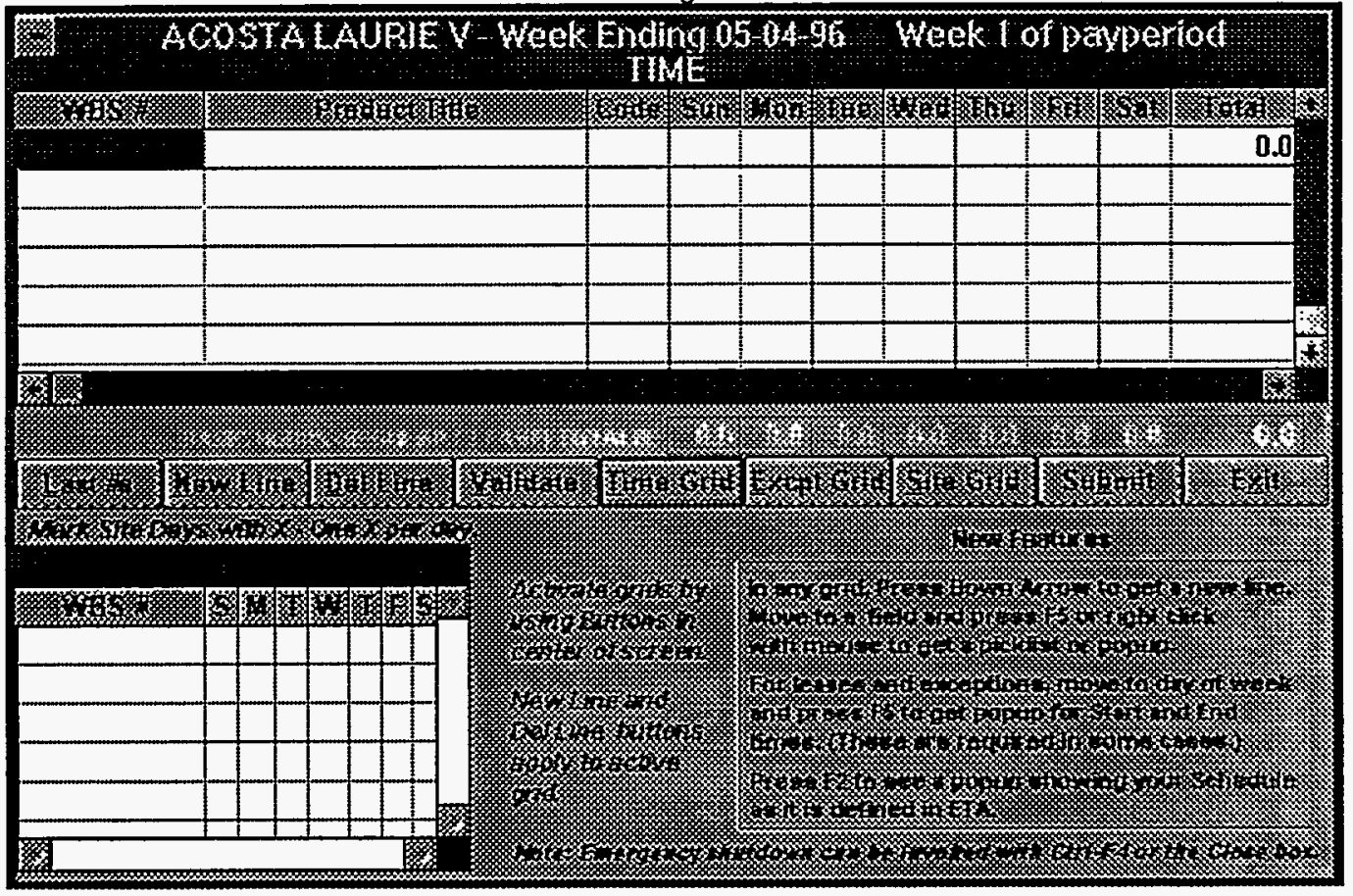

\section{Using the Grids when Filling out a Timecard}

Three grids are used for reporting hours. The "Time" grid is for reporting regular work and leaves which transpire within an Employee's scheduled Tour of Duty and are used in the computation of total "Basic" hours. To check what the scheduled Tour of Duty is, an Employee can press the function key F2. 


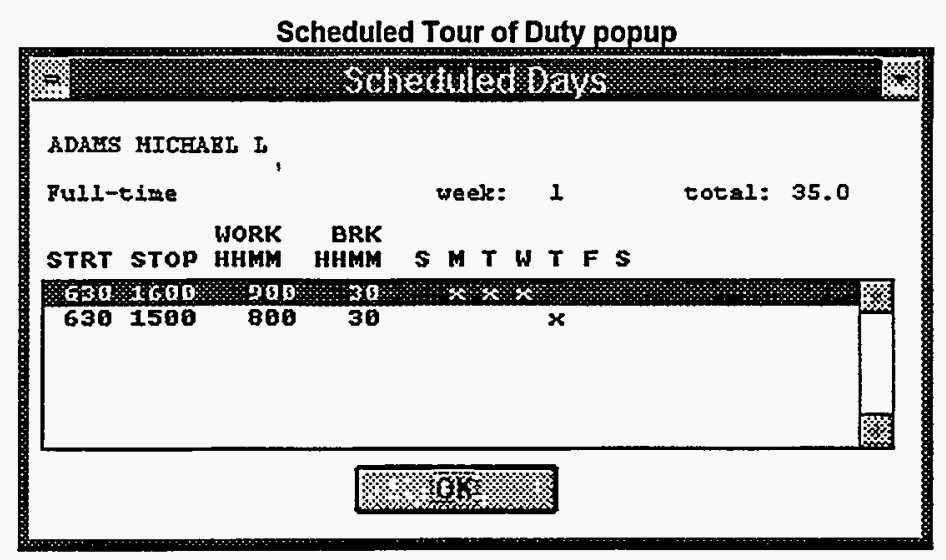

The "Except" grid is behind the "Time" grid and is accessed by clicking on the button labeled "Excpt Grid". Hours reported on the "Except" grid are for hours that are not included in the "Basic" total and generally occur outside the Scheduled Tour of Duty; for instance, hours for overtime, comp time earned or credit hours earned. However, holiday earned occurs within the Tour of Duty scheduled, and credit hours earned, can occur during Tour of Duty hours if the amount of time is less than scheduled break time.

The "Site" grid, located at the bottom of the screen, is used by Employees who earn Remote Site pay. It is accessed by clicking on the button labeled "Site Grid". To return to the "Time" grid, click on the button labeled "Time Grid".

\section{Time Grid}

The Time Grid is used to enter "Basic" hours. This includes paid leaves as well as regular time. For Full time employees, the total of "Basic" hours must equal the total of hours scheduled in the Tour of Duty set up in the ETA system. Also, for each day, the total hours worked must equal the scheduled hours for that day. Part time employees may work more but not less than scheduled hours.

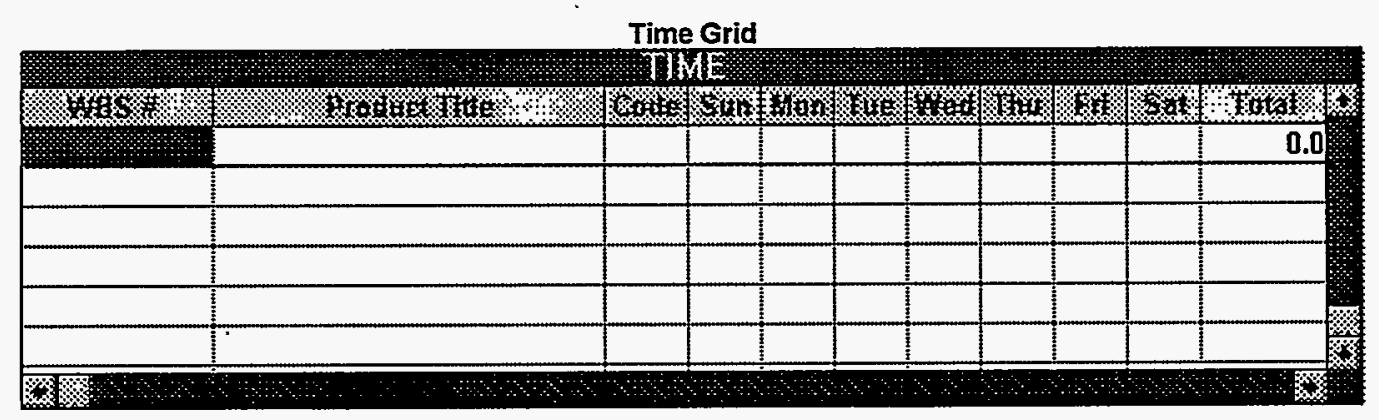

\section{COLUMN TITLE $\quad$ CONTENTS / INSTRUCTIONS}

WBS \#

All hours must be charged to a WBS\#. It can be entered directly or selected from a picklist activated by the right mouse button or the function key F5. If the code for Other (Leave) is selected, a popup for selecting a Leave code will be presented. 


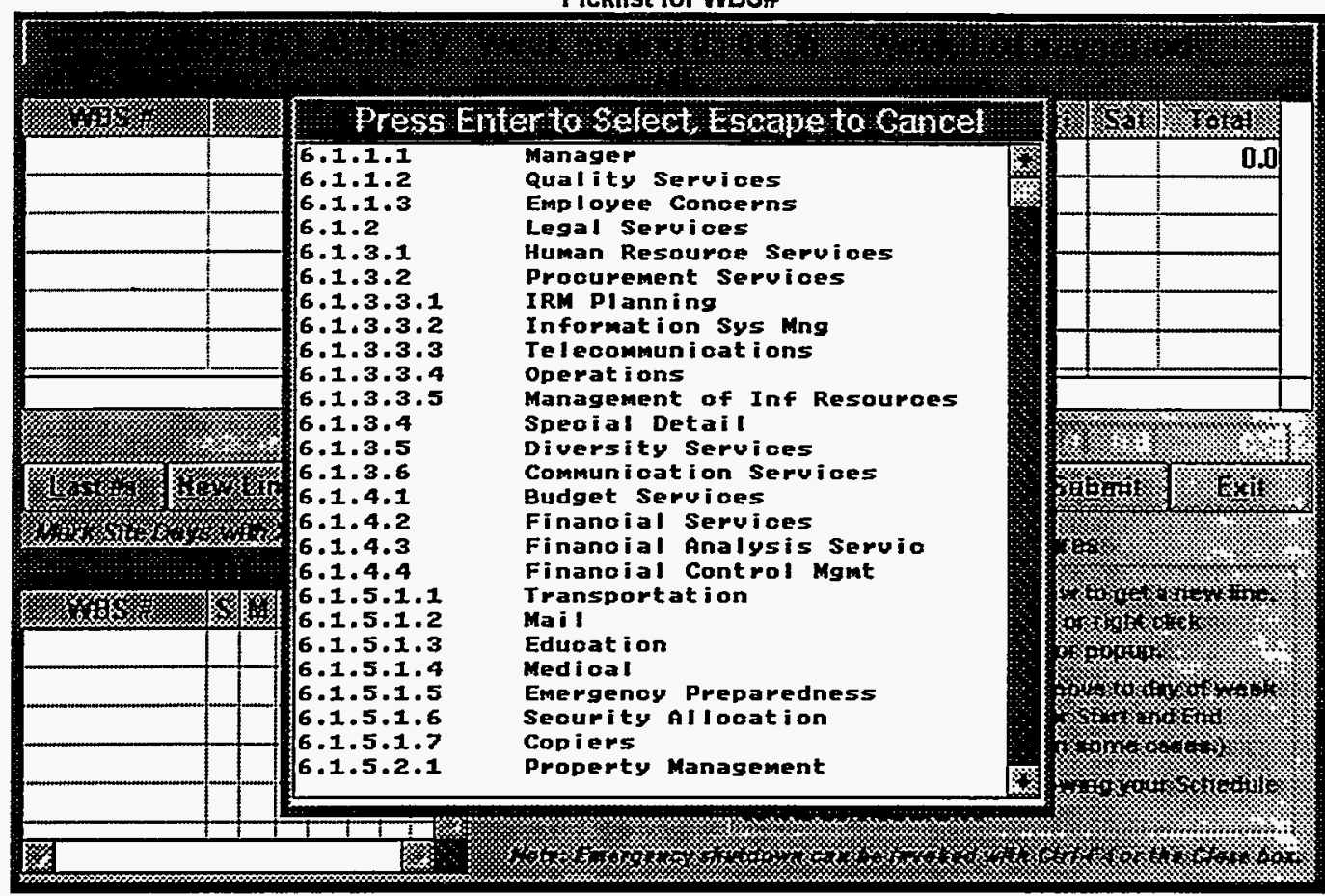

Product Title

Code
This is filled in with the WBS title when a WBS\# is entered or selected. There is also the option to right click with the mouse button or press F5 to get a list of titles to select from. The contents of the list depends on the WBS Table built before as part of the initial setup of the program.

This is filled in as 010 , the regular time code, when a WBS\# is entered or selected unless the WBS\# is for Other (Leave). The Code can be changed by entering a new code or by using a picklist, activated by the right mouse button or F5. The contents of the pick list can be modified by the Timecard Administrator. 
Picklist for Code

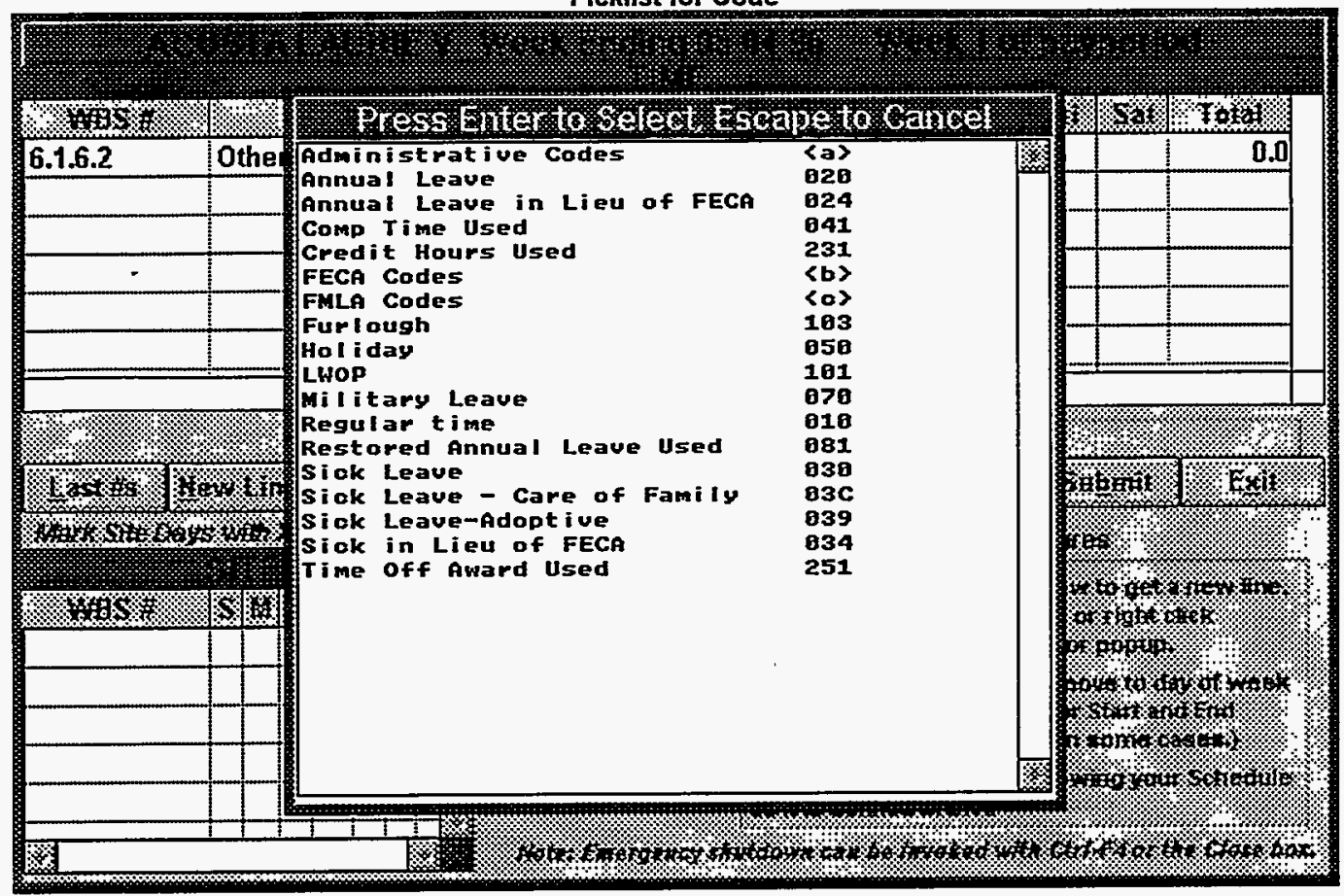

Sun - Sat

If the Code entered previously was 010 , just the hours worked need to be entered on the days worked. If the Code that was previously entered was a leave code, Start and Stop Times must also be entered. Entering a number will cause a popup for this purpose to appear automatically. The popup can be also be activated with the right mouse button or F5.

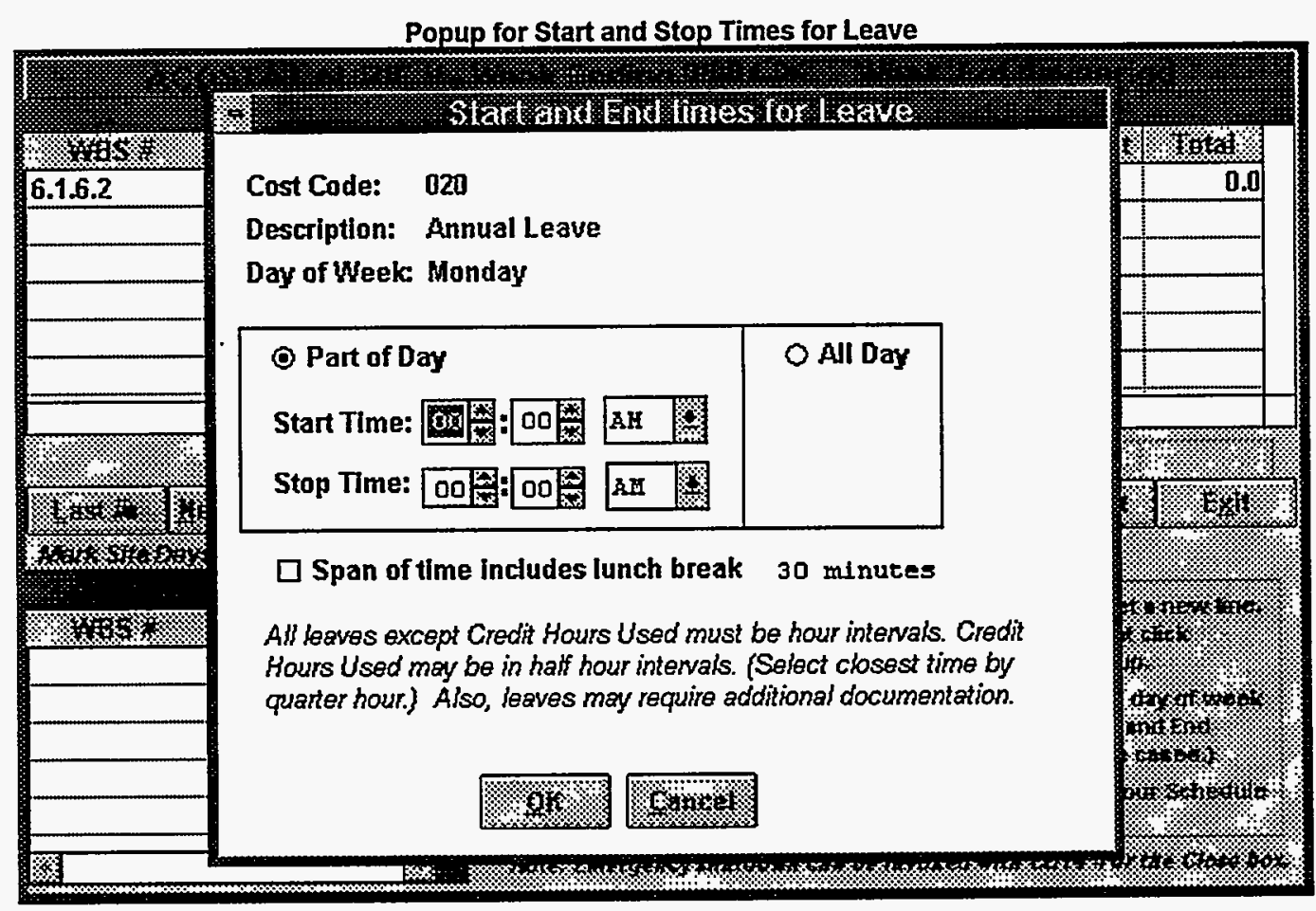


Comments Optional field, for employee use only. This field is not visible on the screen until you tab to it or scroll right.

\section{NOTES}

- Regular time $($ Code $=010)$ does not require Start and Stop Times. Other codes do.

- The span of time is computed from the Start and Stop Times, subtracting lunch break if so indicated.

- The span of time must be in whole hour intervals unless the code is for credit hours used.

- Credit hours used may be in half hour intervals.

- Regular and leave hours may not occur on days not in the Employee's Schedule. The Except grid is used to record unscheduled days and times. F2 will display a schedule popup.

- Holidays will be added to a Time Card automatically. Where Alternate Work Schedules are used, holidays may be moved if necessary.

\section{Site Grid}

Employees who earn Remote Site pay use this grid to mark which days they were at the site and what WBS\# they worked for.

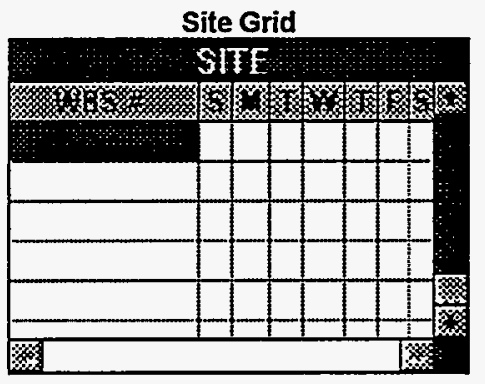

\section{COLUMN TITLE}

WBS\#

S,M,T,W,T,F,S

\section{CONTENTS / INSTRUCTIONS}

This must be one of the WBS\#s used in the "Time" or "Except" Grid. It must be selected by activating the picklist (right mouse button or F5) or by using the New Line button. (See Button Controls.) The list will be built from WBS\#s used in the Time and Except grids.

The employee should mark days worked with an $\mathrm{X}$.

\section{Except Grid}

Hours reported on the "Except" grid are for hours that are not part of the "Basic Hours". Generally, these hours are worked outside the bounds of the Scheduled Tour of Duty. An exception to this rule is credit hours earned. If the hours for Credit Hours Earned are less than or equal to the amount of scheduled break, then these hours may occur within the Scheduled Tour of Duty. Holiday earned may also be within the Tour of Duty. 
The Except Grid

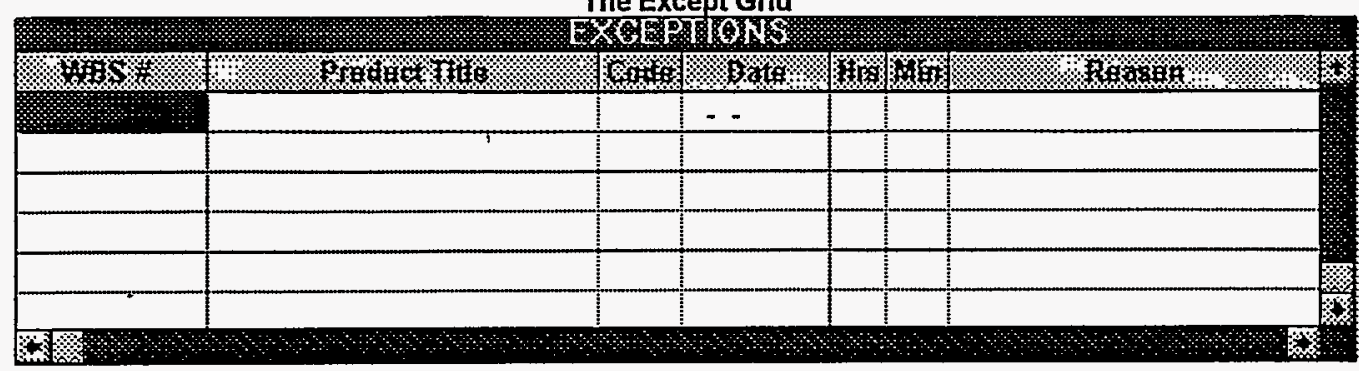

COLUMN TITLE

WBS\#

Product Title

Code

\section{CONTENTS / INSTRUCTIONS}

The Employee enters the WBS\# directly or activates a picklist with the right mouse button or F5. The product title will be filled in automatically based on the WBS\# but the Exception Code will not be filled in.

This is filled in with title when WBS\# is entered or selected. It can also be selected by using a picklist of titles. (The right mouse button or F5 will activate the picklist.)

This is not filled in when the WBS\# is selected. It must be entered directly or selected from a picklist. (The right mouse button or F5 will activate the picklist.) The contents of the Exception Code list can be modified by the Timecard Administrator.

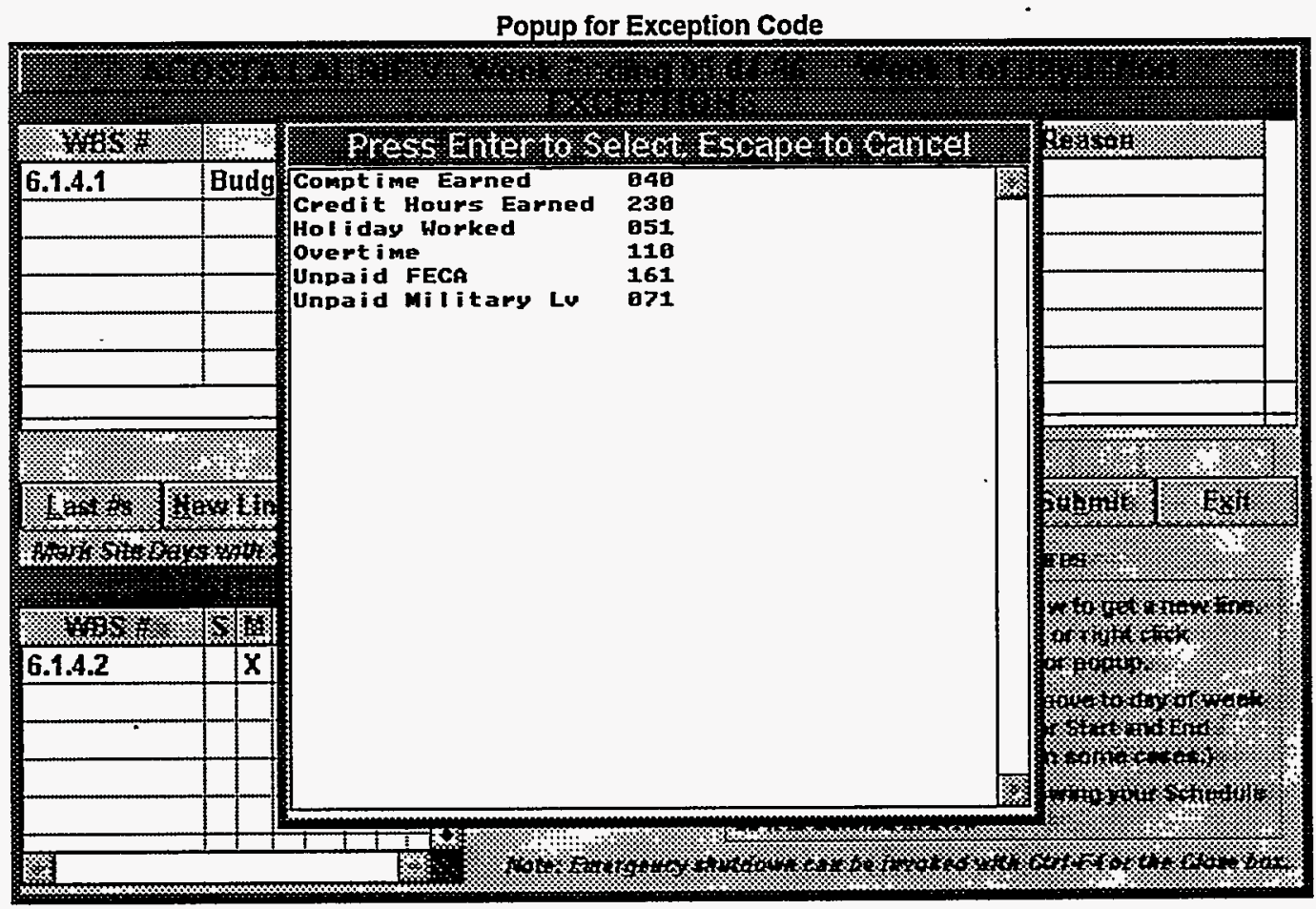

Date

Dates must occur during the current week. The date can be entered directly or selected from a picklist. (The right mouse button or F5 will activate the picklist.) 
Popup for Dates

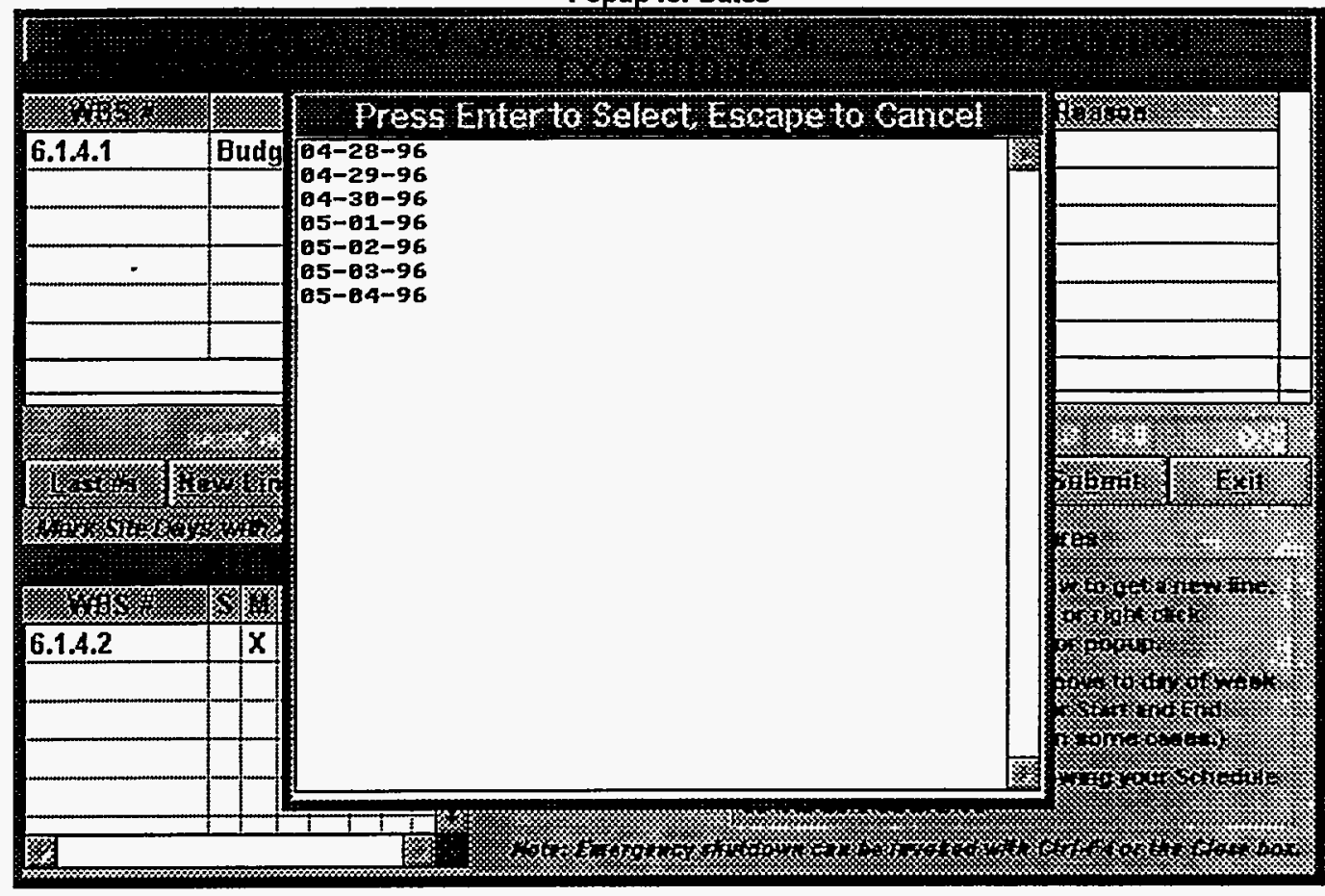

Hours

Start and Stop Times for hours worked are required for exceptions. Entering a number will cause a popup for this purpose to appear automatically. The popup can also be activated with the right mouse button or F5. Computation of the span of time between start and stop time will occur when the user clicks on OK in the popup.

Minutes

This is calculated from the start and stop times entered for the day.

Popup for Exception Start and Stop Times

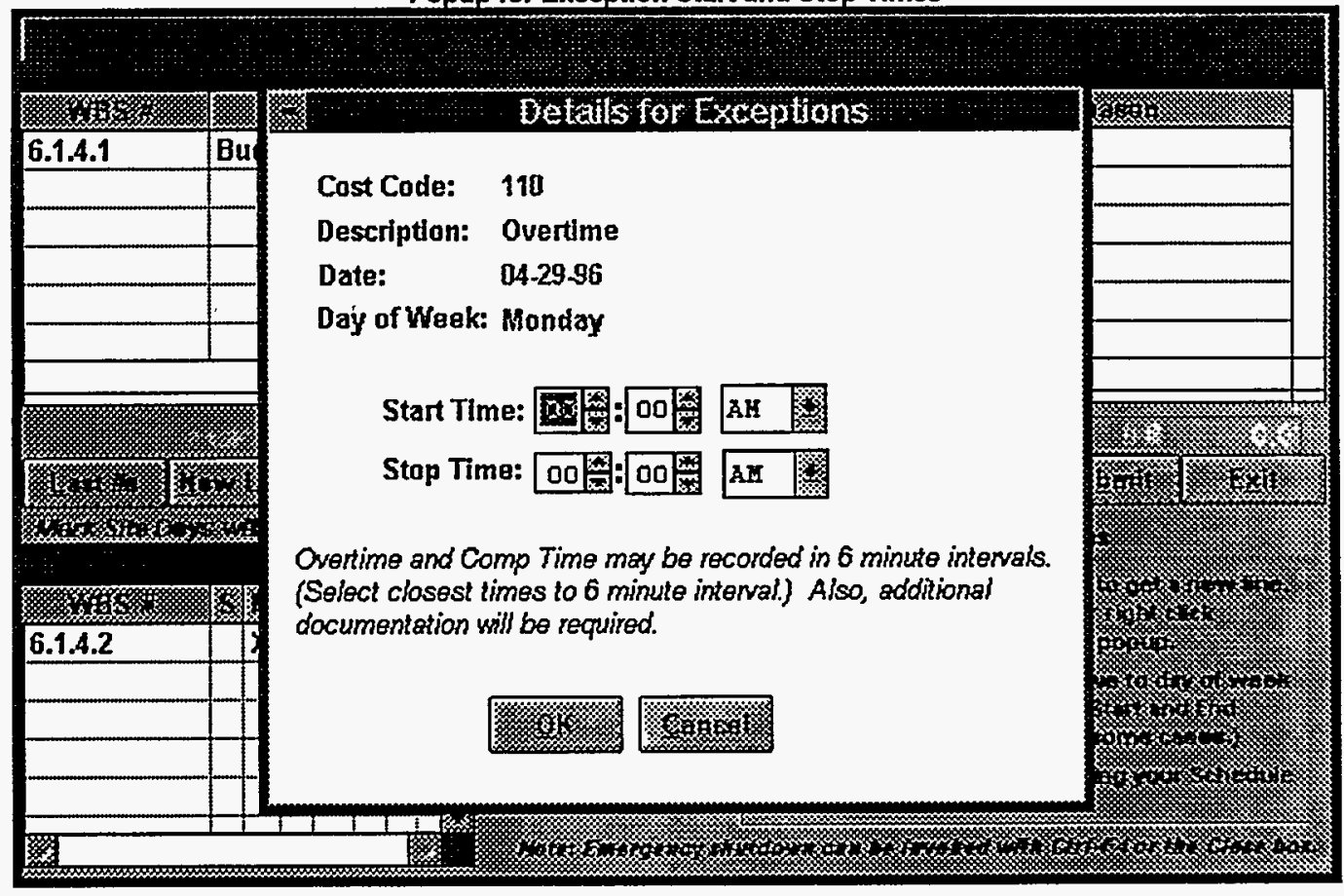




\section{NOTES}

- Hours for Exceptions are not included in the total for "Basic" hours.

- All exceptions require Start and Stop Times.

- For most exceptions, the Start and Stop Times cannot occur during Tour of Duty schedule.

- There is no provision for break in Exceptions. The Employee must make two entries if there was a break.

\section{Button Controls}

These buttons always remain in the center of the screen. The actions of New Line and Del Line will apply to whichever grid is active.

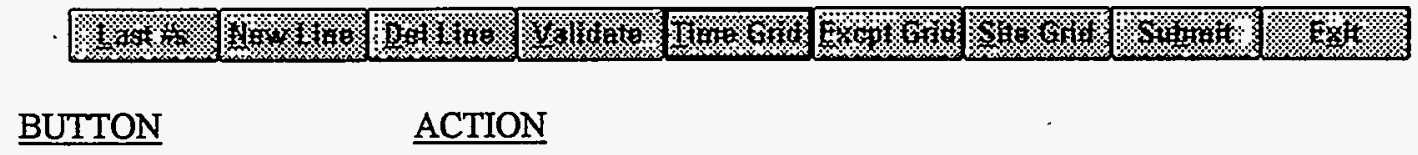

Last \#s

Retrieve all the WBS\#s from last week which were code 010 (regular time).

New Line

The result of clicking on this button depends on which grid is active.

TIME GRID: If the "Time" grid is active, a dialog box will appear with buttons WBS\#... and Leave.... The WBS\# button takes the user to another dialog box where WBS\#s can be selected from a hierarchical group of list boxes. The Leave button presents a similar dialog box. Once OK is clicked, a new line will be filled in with WBS\#, Product Title and Code. (Note, pressing the down arrow is another way to get a new line; it will be blank.)

EXCEPT GRID: A dialog box will appear with a hierarchical group of list boxes and another list box for selecting the Exception code. The result will be on new line filled in with WBS\#, Product Title and Code.

SITE GRI: A list of WBS\#s used in the Time and Except grid will appear. After a selection is made a new line will be added, filled in with the WBS\#.

Result of New Line button when in the Time Grid

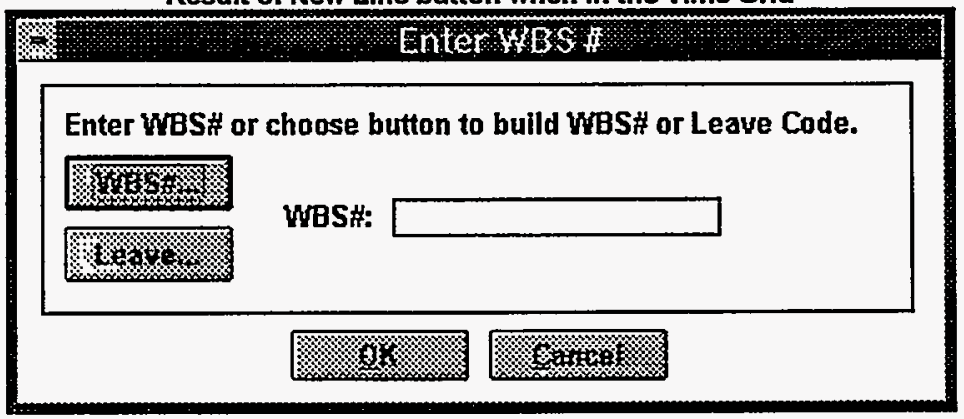


Result of WBS\#... button

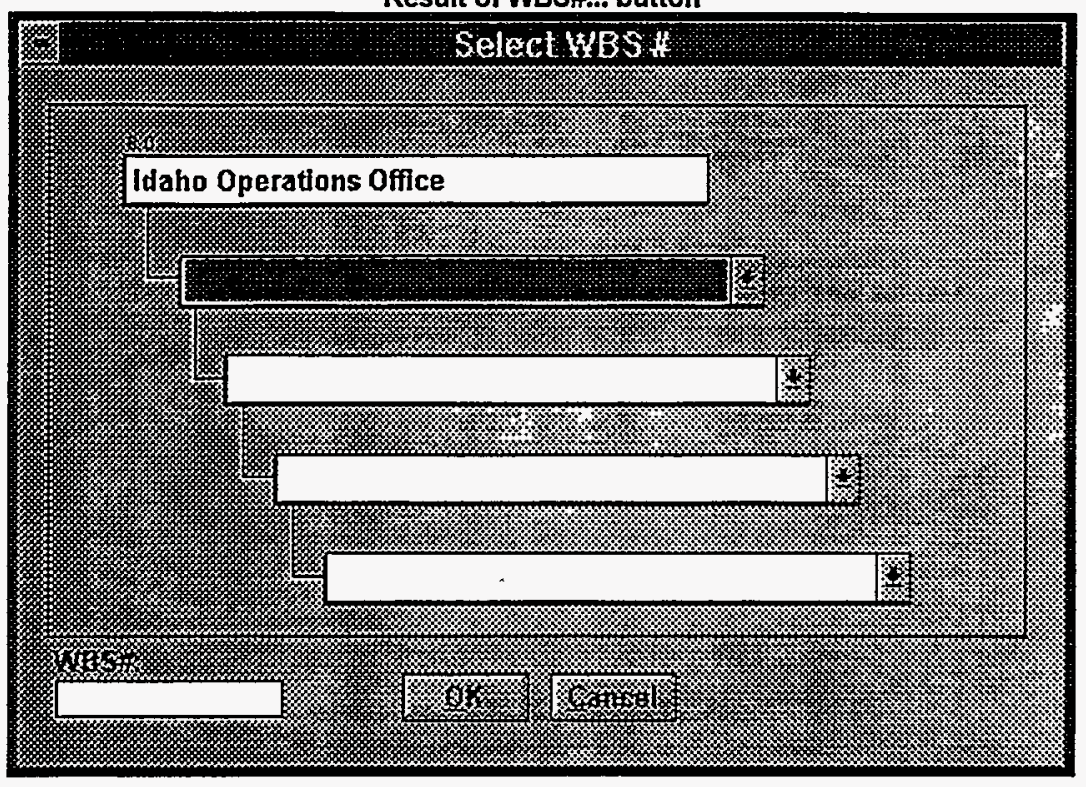

Result of Leave... button

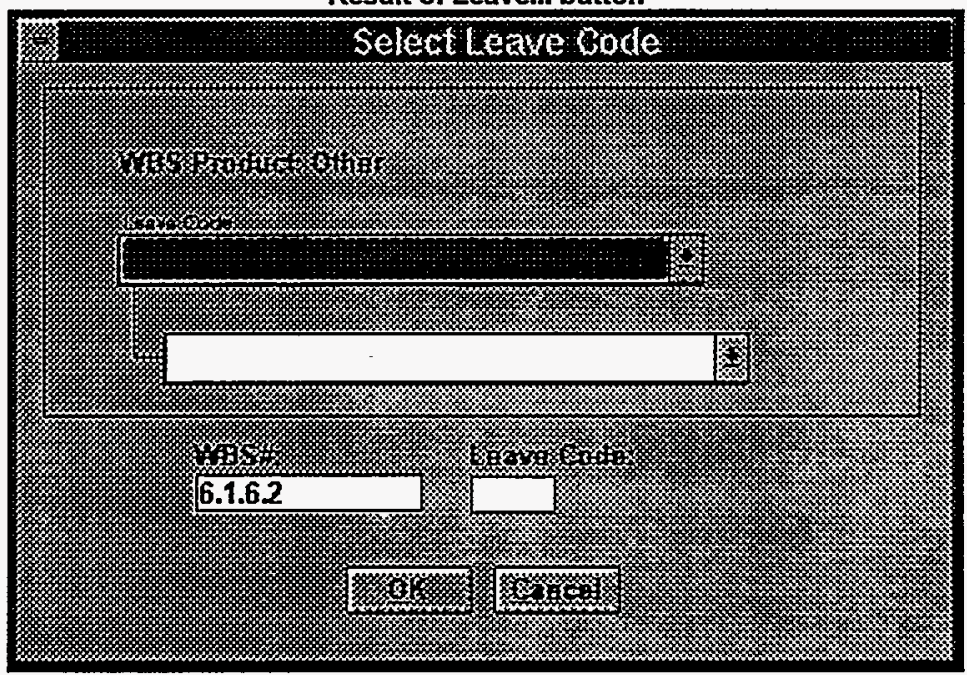




\section{Result of New Line button when in the Except Grid}

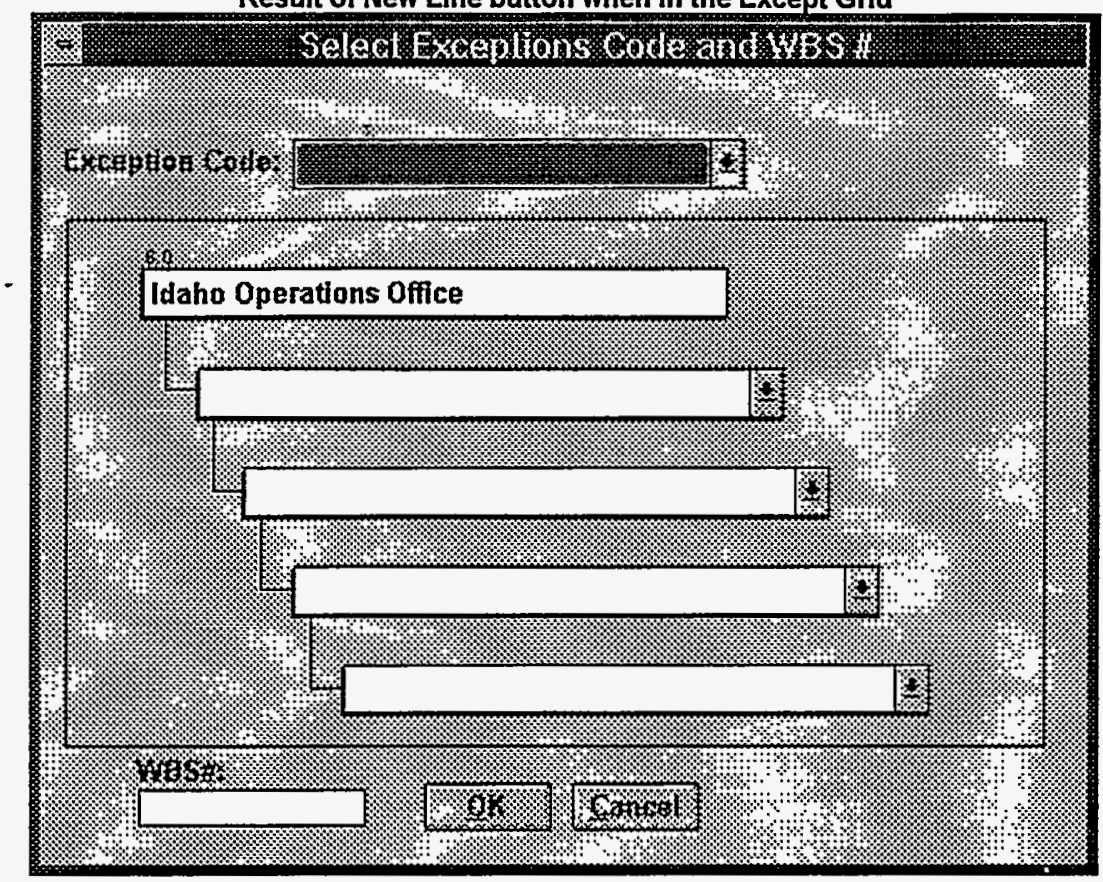

Del Line

Delete current line in the active grid. (Note highlight or cursor to determine which grid is active and which line is current.)

Validate

Perform a complete validation check on timecard data. Users may check for validation and completeness prior to submittal by pressing this button. The data entered must be within the Tour of Duty restrictions and be complete for the week to considered Valid.

Time Grid

Switch to Time Grid.

Excpt Grid

Switch to Excpt Grid.

Site Grid

Switch to Site Grid.

Submit

Submit Timecard. (A validation check will be performed automatically. Only valid timecards can be successfully submitted.)

Exit

Exit Timecard. (A partial validation check will be performed first. Ignores cases where hours are less that scheduled.)

\section{Adding Lines}

There are two ways to add lines. To add a blank line to any of the grids, press the Down Arrow. To get a popup to assist in selection of data to add, click on the New Line button in the center of the screen. (See section on Button Controls.)

\section{Deleting Lines}

To delete the current line in the active grid, click on the Del Line button in the center of the screen. (See section on Button Controls.) 


\section{Filling out a Time Card for Others}

Employees can submit timecards for the current week for other employees who are a member of the same Timekeeper group by using the option Submit Timecard for Another from the File menu. A list of employees will be presented in a list box. The Employee can click on the employee name and then click on OK.

Submitting a Timecard for Another

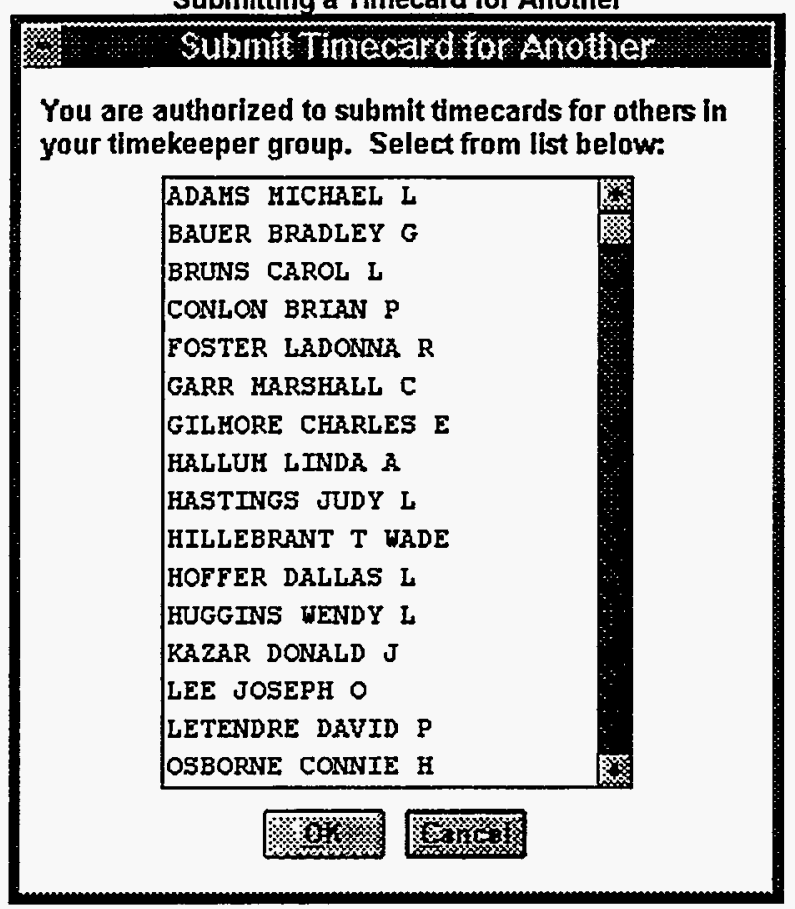

The Current Timecard window will then appear, with the name of the Employee whose Time Card is being edited in the window title. If the timecard is submitted, a message will appear, notifying the submitter that the owner of the Time Card will be notified that his timecard was submitted by another. The next time that the owner of the Time Card uses Timecard, he will be alerted that there exists a Time Card submitted by another person. The Timecard report will always show who submitted the Time Card as well as the owner.

Timekeepers may submit timecards for the current week for any Employee by using the option Submit Current Timecard from the TimeCard submenu under the Timekeeper menu. The Timekeeper selects a Timekeeper group from the drop down list. Only those Employees with unsubmitted timecards for that Timekeeper will appear. When the Timekeeper clicks on an Employee name and then clicks on the button Edit/Submit TimeCard, the Current Timecard screen will appear with the name of the Employee in the window title. If the Time Card is submitted, the notifications for a Time Card being submitted by another will occur as described in the previous paragraph. 
Submitting for Another from the TimeKeeper menu

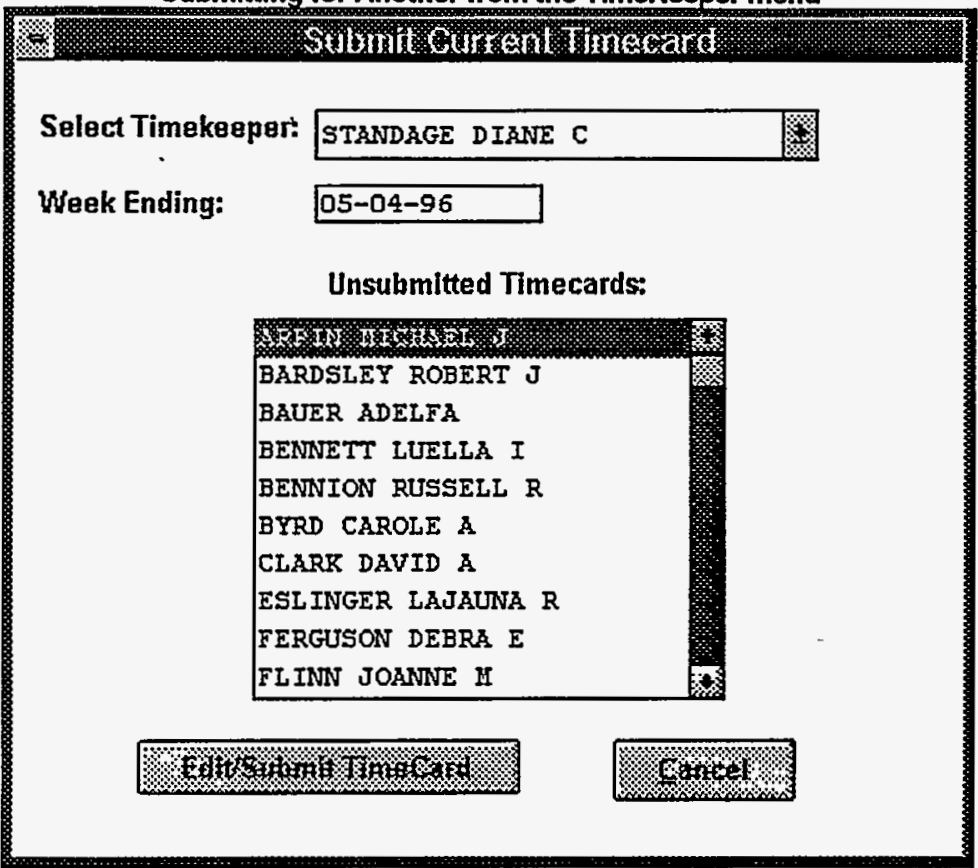

Timekeepers can also use the option Submit Past Due Timecard from the TimeCard submenu under the Timekeeper menu. The Timekeeper first selects a week from the drop down list, clicks on an Employee name and then clicks on Edit/Submit TimeCard. The Current Timecard window will appear, with the name of the other Employee in the window title. If the Time Card is submitted, the notifications for a Time Card being submitted by another will occur as described above.

Supervisors can submit Time Cards for others using the same options from the Supervisor menu.

Administrators can access all menus plus the Administrator menu which, in addition, has an option to Unsubmit a Timecard.

\section{Printing a Time Card}

There are two print options Employees can use to print a Time Card. To print a timecard for the current week before it has been submitted, an Employee can select Print Current Timecard from the File menu. If a Time Card has already been submitted, or if an Employee wants to print Time Cards submitted in previous weeks, he can select Print Submitted Timecard from the File menu.

\begin{tabular}{|c|c|}
\hline \multicolumn{2}{|c|}{ Current Timecard } \\
\hline \multicolumn{2}{|c|}{ 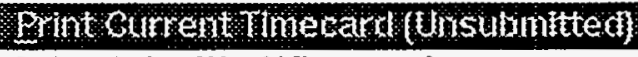 } \\
\hline \multicolumn{2}{|c|}{ Print Submitted Timecard } \\
\hline \multicolumn{2}{|c|}{ Submit Timecard for Another } \\
\hline Exit & CTRL+F4 \\
\hline
\end{tabular}

Timekeepers, Supervisors, and Administrators can print any submitted timecards. Timekeepers can select the option Print Completed Timecards from the Timecard submenu under the Timekeeper menu. Supervisors can select the option Print Completed Timecards from the Supervisor menu. Administrators can use either option. 


\begin{tabular}{|c|c|c|}
\hline & \multicolumn{2}{|l|}{ Tinaseepen } \\
\hline & \multicolumn{2}{|l|}{ Timekeepers } \\
\hline \multicolumn{3}{|c|}{ Submit Current Timecard } \\
\hline \multicolumn{3}{|c|}{ Print Completed Timecands } \\
\hline \multicolumn{2}{|c|}{$\begin{array}{l}\text { List Unsubmitted Timecards } \\
\text { Submit Past Due TimeCard for Another }\end{array}$} & ata \\
\hline & $\begin{array}{l}\text { Opuate Promle; Tou } \\
\text { Export TimeCard D }\end{array}$ & $\begin{array}{l}\text { of Duty and Employee Info } \\
\text { ata to ETA }\end{array}$ \\
\hline
\end{tabular}

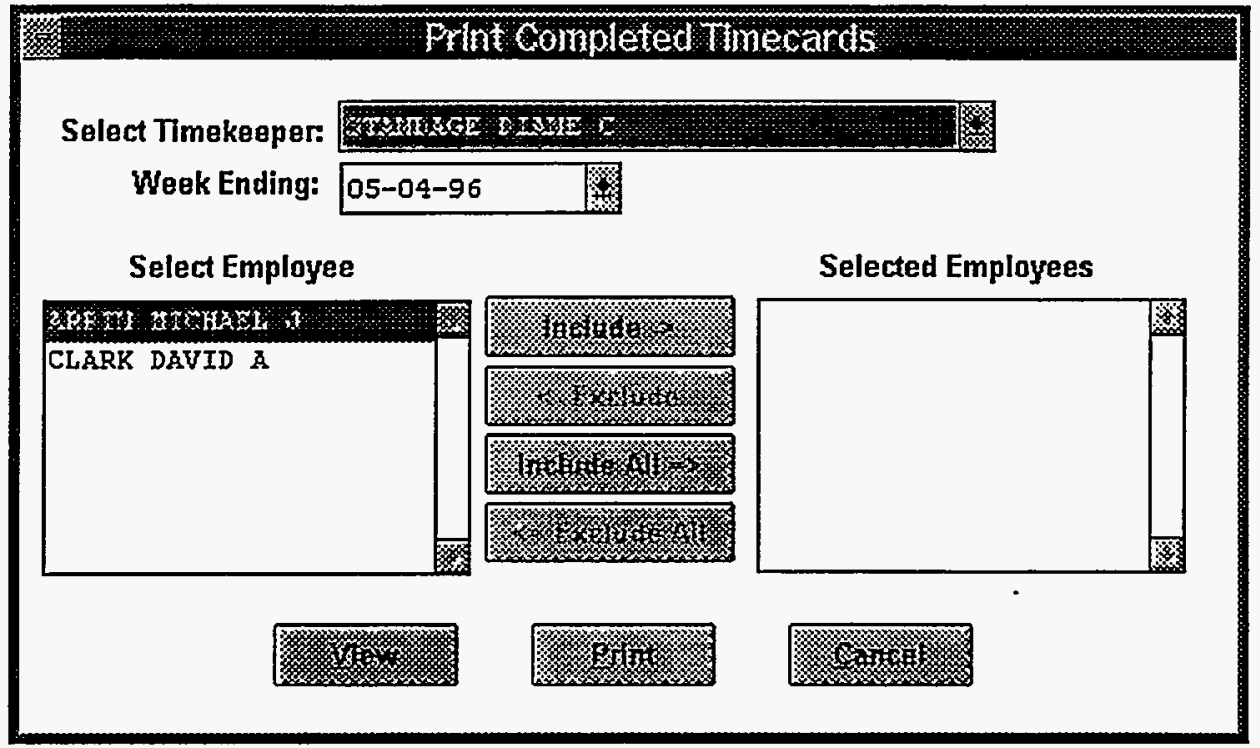

Once a Timekeeper is selected from the drop down list, the names of all that Timekeeper's Employees who have submitted a Time Card will appear in a scrolling list box. One or more names can be moved from the available list to the selected list and then the Time Cards can be previewed or printed.

\section{Assigning Employees to Timekeepers}

One of the requirements for an Employee to enter Time Card data, is that he be assigned to a Timekeeper in the Timecard system. This requirement is separate and in addition to the ETA function to assign Employees to a Timekeeper. Either a Timekeeper or Administrator must make the assignment in Timecard using the Timekeeper option under the Timekeeper menu. The Timekeeper is selected from the drop down list and the button Assign Employee is clicked. (If a needed Timekeeper is not on the list, that Timekeeper can be added. - See Adding Timekeepers.) A list of Employees will appear. When an Employee is selected, his name is added to the list that shows all Employees assigned to the selected timekeeper. If the Employee is already assigned to another Timekeeper, his assignment is switched. The Employee does not need to be unassigned first. 


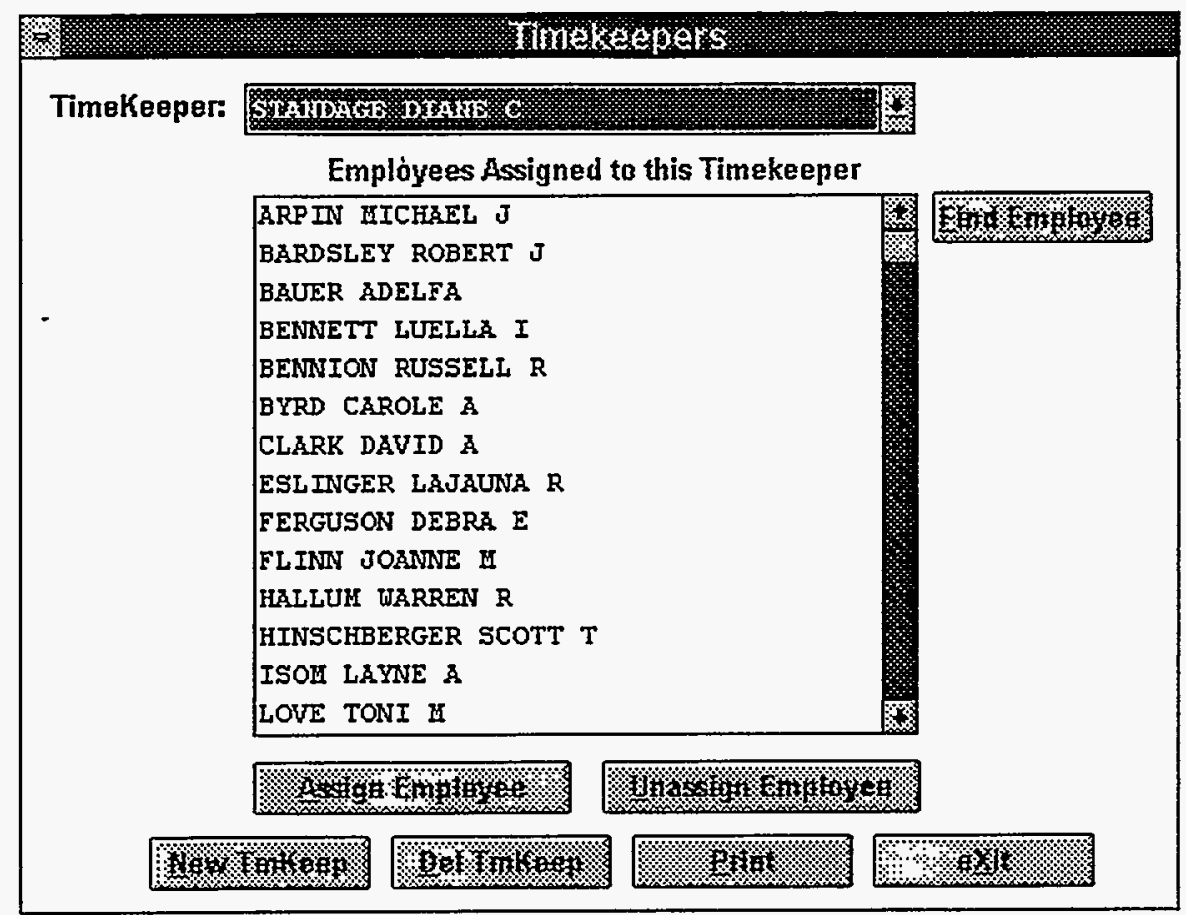

\section{Looking up an Employee-Timekeeper Assignment}

To determine who is the timekeeper for a given Employee, a Timekeeper or Administrator can use the option Timekeeper under the Timekeeper menu. The button Find Employee will present a list of all Employees. Once a selection is made, the appropriate Timekeeper will be shown in the Timekeeper drop down list with all the Employees assigned to that Timekeeper showing in the scrolling list box.

To get a comprehensive report of all Employee-Timekeeper assignments, the Print button in this screen can be used.

\section{Missing Data}

A number of data elements must be in the system for an Employee to be able to use the System:

Employee name

$S$ number or some other unique identifier in its place

Network ID

Social Security number

Timekeeper assignment

ETA data elements

To assist the Timecard Administrator in setting up Employee information, the Check for Missing Data option can be used. It is located under the Timekeeper menu. (For further instruction on how to initialize data files, see the document: Installation Instructions.) See also: Looking up an Employee-Timekeeper Assignment.

\section{ETA Functions}

Timecard data needs to be processed in ETA. At the beginning of the pay period, Timekeepers may need to transfer employee changes they have made in ETA to Timecard so that the Tour of Duty validations will be correct. To have the schedule changes in ETA take effect in Timecard, the Timekeeper must select the Update Profile, Tour of Duty and Employee Info option from the Timekeeper menu. The Timekeeper will need to specify the Block Code for their office and the Timekeeper Code for the group of Employees to be updated. 


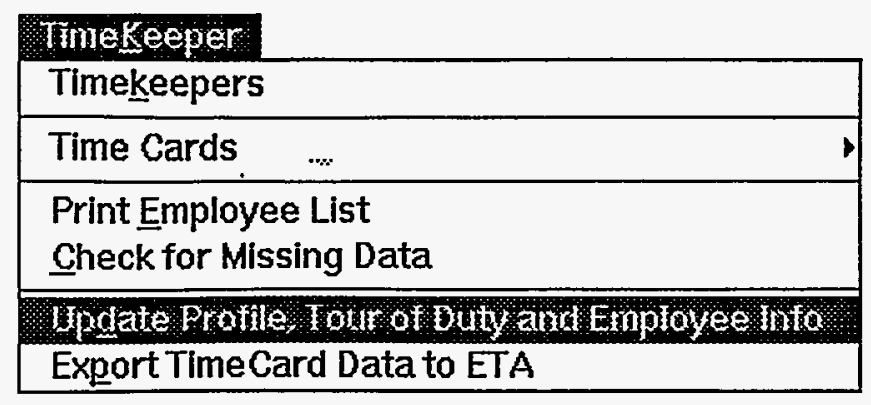

Setting up Timecard with Current Tour of Duty Schedules

Update Profite Tour of Duty and Employee lofo

ETA Block Code: $\quad 512$

ETA Timekeeper Code: 608 (Press F5 for list.)

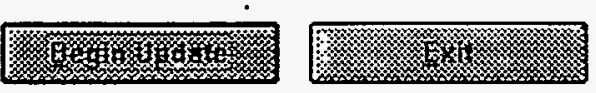

At the end of every two week pay cycle, the Timekeeper will send Timecard time and attendance data to ETA, using the option Export TimeCard Data to ETA from the Timekeeper menu.

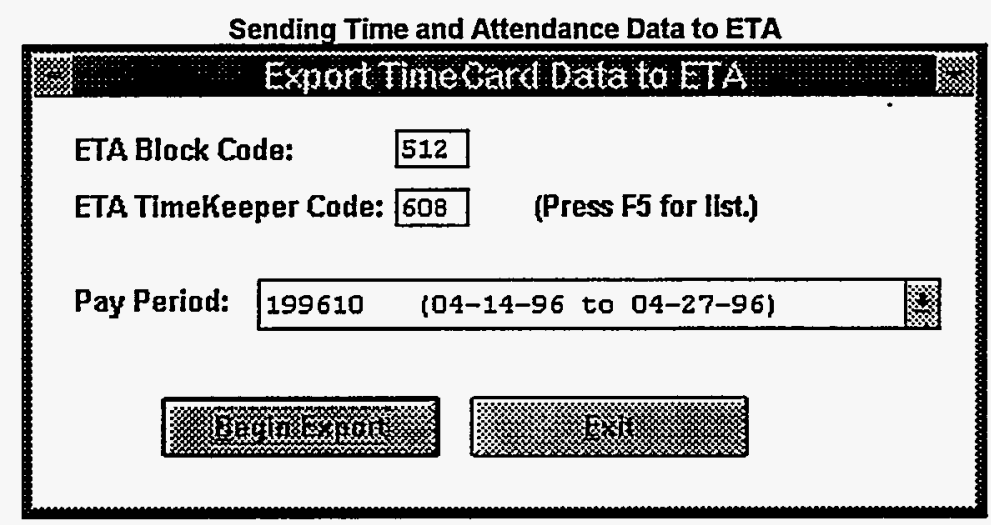

The Timekeeper needs to have set up the ETA Pay Period to correspond to the pay period to be selected in Timecard. Changes will be made to ETA data files on the hard drive and the ETA Data diskette. Once the Export is completed, the Timekeeper should exit Timecard and then begin ETA to read in the time and attendance data.

\section{Table and System Variables Maintenance}

Assigning the WBS\# for "Other" - From the Tables menu, the Administrator can select System Variables and fill in the WBS\# for Other (Work) and Other (Leave). This needs to be performed only once. 
Setting up "Other" code and Office Block

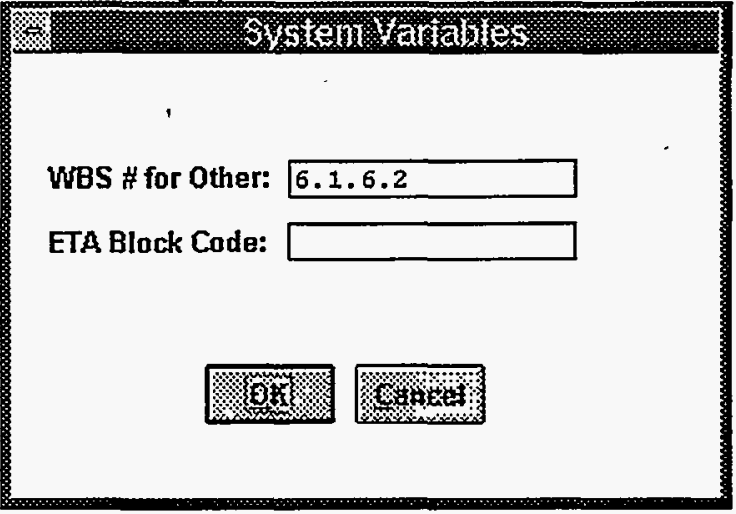

Assigning the Office Block Code for ETA - From the Tables menu, the Administrator can select System Variables and fill in the block code assigned to the Office. This needs to be performed only once.

Adding a Holiday - If there is a holiday that is being added to the standard list by Timekeepers in ETA, the Administrator must also add it in Timecard. From the Tables menu, select ETA Tables, then ETA Holidays. This option will rarely be needed.

Leave Codes - Although validation is actually done against all the "Basic" type of codes in the entire ETA HOURS_CD table, the popup list used for codes when a Timecard is being filled out will consist only of the codes set up in this table. The Timecard Administrator can customize this list to include only the codes most often used. $\langle a\rangle,\langle b\rangle$, and $\langle c\rangle$ are optional entries, for use in building a hierarchical picklist of codes. See the next three paragraphs.

Maintenance of Leave Codes used in picklist

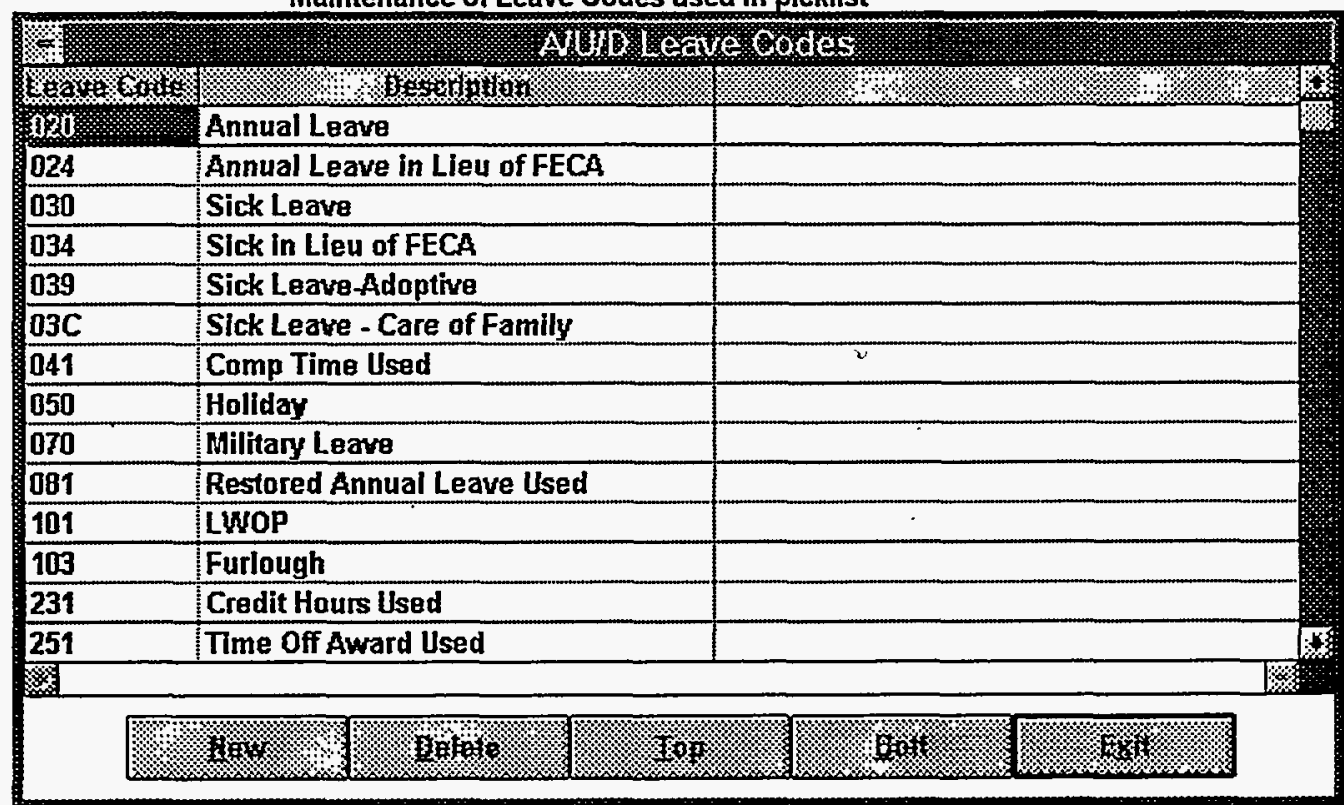

Admin Leave Codes - This is optional. If the $<a>$ line is left in Leave codes, then a sublist of Admin leave codes may be built.

FECA Leave Codes - This is optional. If the $<\mathrm{b}>$ line is left in Leave codes, then a sublist of FECA leave codes may be built. 
FMLA Leave Codes - This is optional. If the $<\mathrm{c}>$ line is left in Leave codes, then a sublist of FMLA leave codes may be built.

Exception Codes - This controls the contents of the popup of common codes used in the Exceptions grid. (Reporting rule is that they not be included in the total "Basic" hours.)

\section{Registering Émployees}

One of the requirements for an employee to access Timecard is to be registered in the Employee by the Timecard Administrator with the A/U/D Employee option under the Admin menu. The userid, S number and SSN must be present. If an employee is in the table but is not recognized by the Timecard system, the network login script for that employee should be checked for the line:

This command is case sensitive.

$$
\text { MACHINE }=\text { "\%LOGIN_NAME" }
$$

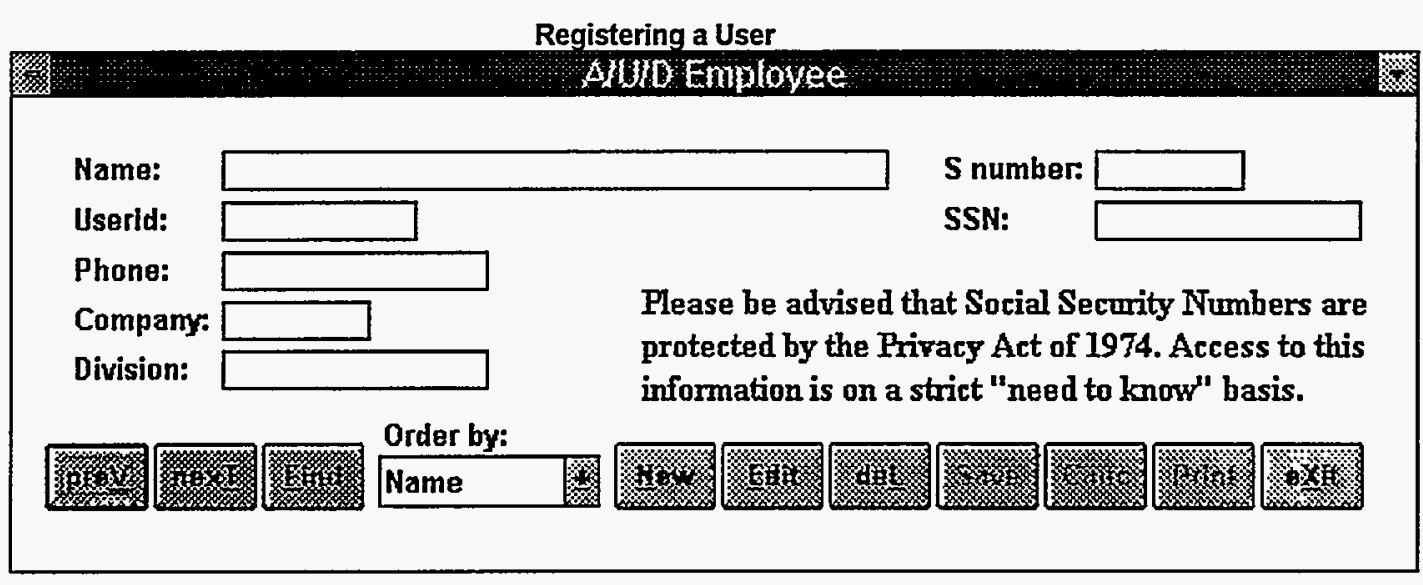

The fields are read-only in the A/U/D Employee screen until the Edit button is clicked. Then the changes must be saved or canceled. An Employee record may be located by using the Find button. The list that appears will be in the order specified in the Order by popup. The Administrator may search by Name or $S$ number.

\section{Adding Timekeepers}

The Timekeeper list is maintained in Timecard with the Timekeepers option under the Timekeeper menu. To add a Timekeeper, a Timekeeper or Administrator clicks on the New TmKeep button. A list of employees will be presented. Once an employee is selected from the list, he will be added to the Timekeeper list and his name will appear in the drop down list box. Employees can then be assigned to the Timekeeper. (See Assigning Employees to Timekeepers.) To delete a Timekeeper, a Timekeeper or Administrator first selects the Timekeeper to be deleted from the drop down list, then clicks on Del TmKeep.

\section{Adding Supervisors}

Supervisors who own projects need to access the WBS\# Usage option on the Supervisor menus. Supervisors who own people need to be able to edit or print Time Cards. Access to these options, which are on the Supervisor menu, is set up by the Timecard Administrator using the Supervisors option on the Admin menu. 


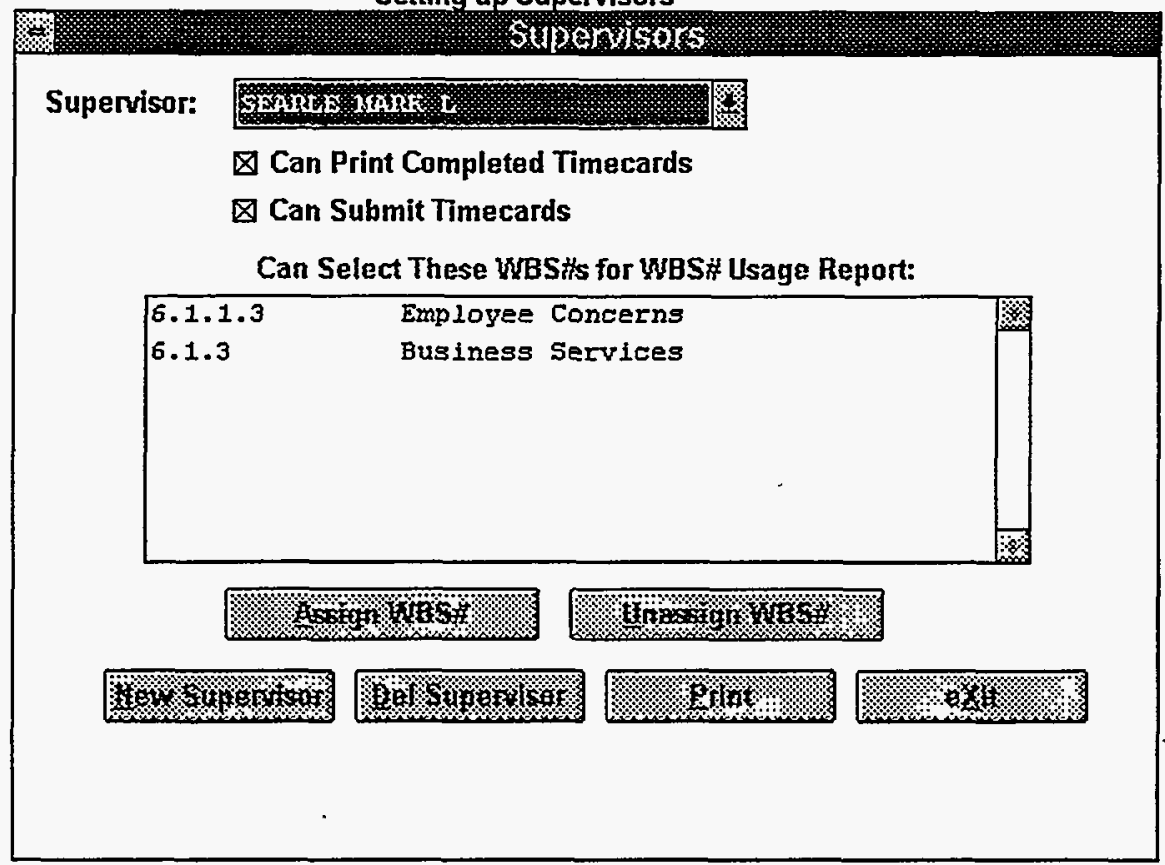

The Supervisor drop down list consists of all designated Supervisors. To add a Supervisor, the Timecard Administrator clicks on the New Supervisor button. A list of employees will be presented. Once an employee is selected from the list, he will be added to the Supervisor list and his name will appear in the drop down list box. To delete a Supervisor , the Administrator first selects the Supervisor from the drop down list, then clicks on Del Supervisor.

If this Supervisor needs to view or print see completed Timecards, then the check box for Can Print Completed Timecards needs to be checked. If this Supervisor needs to be able to submit timecards, then the check box for Can Submit Timecards needs to be checked. Access to the corresponding options on the Supervisor menu is controlled by these settings.

Supervisors who own WBS\#s will need to be able to print a WBS\# Usage Report. Which WBS\#s they can get a report for are listed in the scrolling list box. To add to the list, the Timecard Administrator clicks on Assign WBS\#. To delete a WBS\# from the list, the Administrator first clicks on the WBS\#, then clicks on Unassign WBS\#.

\section{Adding Administrators}

Administrators may be added or deleted from the Administrators group using the Adminstrator's option on the Admin menu. To add another Administrator, the Timecard Administrator clicks on the button New Admin. To remove an Administrator, the Timecard Adminstrator first clicks on a name in the scrolling list box, then clicks on Del Admin. 
Adding Administrators

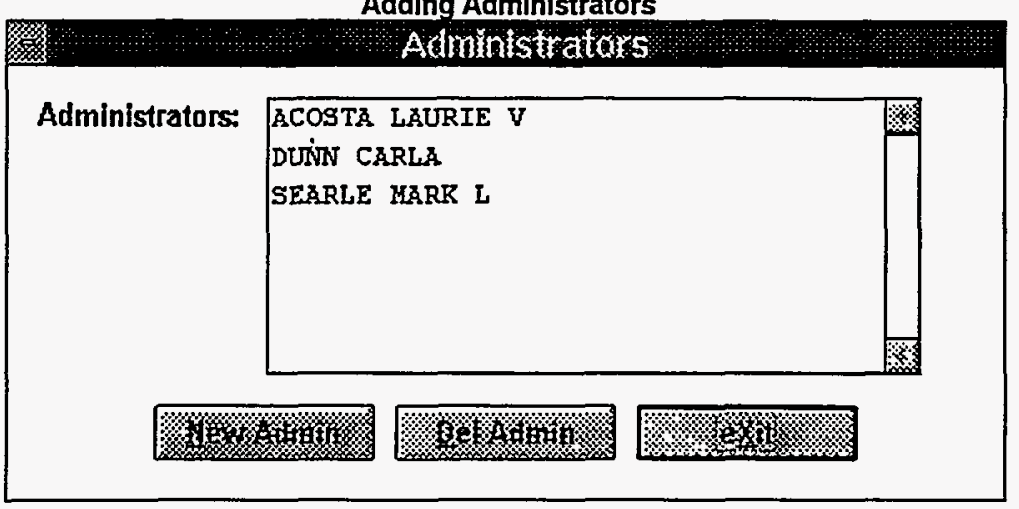

\section{Performance}

These options are on the Admin menu.

Delete Timecards Older than 4 weeks - For optimal performance Timecards older than 4 weeks should be deleted from the system. A good time to perform this function is a week after ETA processing for a pay period has been completed. This system was designed to be collection system for ETA, which is the official record for Time and Attendance data.

Rebuild Program Indexes - Deleted records need to be permanently removed from the database and indexes which affect the performance of the system need to be rebuilt periodically, preferably weekly. This function can be performed only when no other users are using the system.

\section{WBS Usage Report}

Supervisors may be able to get a report on what is being reported against a particular WBS\# or family of WBS\# for a given week by using the WBS\# Usage option on the Supervisor menu. To print a report, a Supervisor first selects a WBS\# and Week from the drop down list boxes, then clicks on View or Print. The contents of the WBS\# drop down list is set up for each Supervisor by the Timecard Administrator. (See Adding Supervisors.) The report will show names of employees, quantity of hours, and day the time was charged.

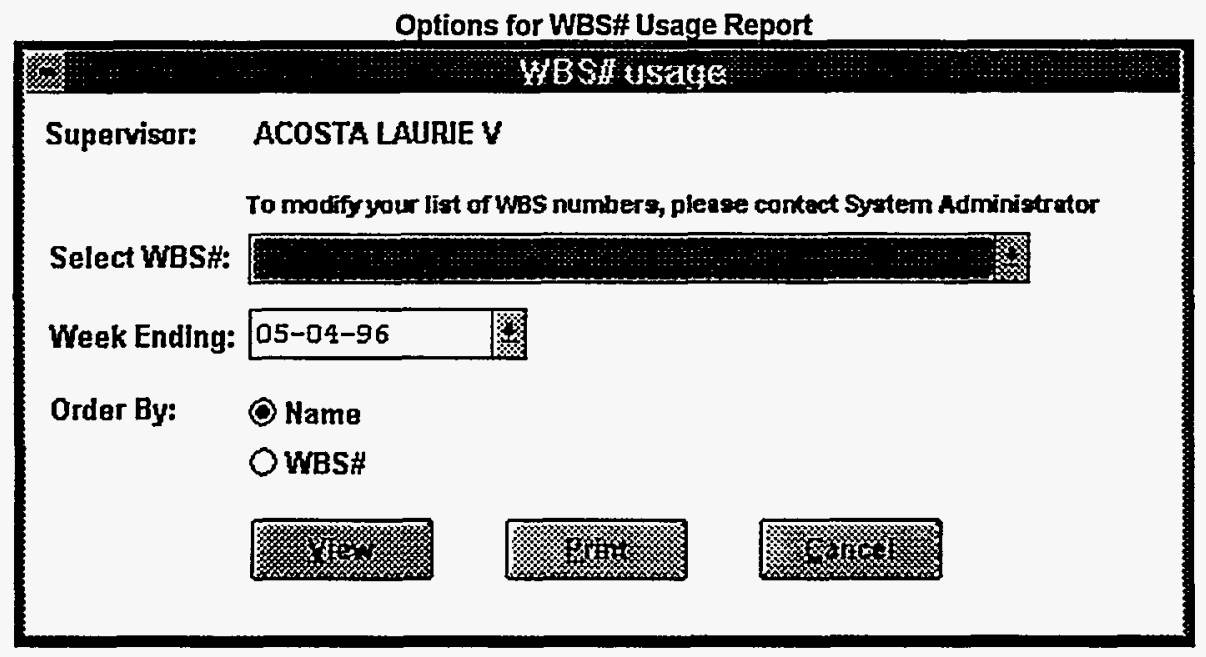


. 